Journal of Sustainability, Environment and Peace

Homepage: http://www.jsep.uonbi.ac.ke

\title{
Sub-National policy Readiness as Regards the Planet's Carrying Capacity and Environmental Sustainability in Kenya
}

\author{
Nzioka J. Muthama \\ Wangari Maathai Institute for Peace and Environmental Studies, University of Nairobi
}

Article history:

Received: 04 January 2019

Received in revised form: 29 January 2019

Accepted: 30 January 2019

Available Online: 04 February 2019

Corresponding Author

Email Address: jmuthama@uonbi.ac.ke

Keywords:

Sustainability,

Planetary boundaries,

County Integrated Development Plans, Peace

\begin{abstract}
The achievement of global sustainable development goals subject to planetary boundaries will mostly be determined at national and at sub-national level as regards contribution to cultures, economies, material use, and waste generation. This paper seeks to investigate planetary and Kenya's county boundaries as development targets from a county development plan perspective. The methodology provides an important tool for counties to play a more fulsome and active role in global sustainable development. Content analysis of the nine limits, namely: climate change, novel entities, ozone depletion, aerosol loading, ocean acidification, biogeochemical flows, freshwater use, land-system change, and biosphere integrity, was performed in the context of the respective County Integrated Development Plans (CIDPs) 2018-2023. A total of 22 CIDPs for 22 counties are analysed to capture the content entailing issues pertaining to the above nine limits. Correlation analysis of the counts of the limits were generated and discussed. It was observed that the CIDPs cover between 30 to $60 \%$ of the expected content of the limits. This is a pointer to the extent to which the counties, and hence Kenya as a country, are ready as regards addressing planetary boundaries at local level. Further, correlation analysis on the counts on planetary boundaries versus peace issues revealed positive correlation between biodiversity and peace, with a correlation coefficient of 0.575 . It is interesting to observe that the counties having strategies on biodiversity have associate peace initiatives. This is a pointer that promotion of biodiversity conservation is closely relate to peaceful outcomes.
\end{abstract}

\section{Introduction}

Sustainable development calls for suitable standards of living for current and future generations while living within the planet's carrying capacity (Dearing et al. 2014). In recent years, there is increasing interest in sustainable development, assessment of which requires quantification of both bio-physical environmental boundaries and social conditions. Rockstrom et al. (2009) initially proposed a suite of planetary system boundaries. The approach provides a relatively simple, easily understood, 'snapshot' of progress toward biophysical limits. Steffen et al. (2015) updated the framework, adjusting current values and better defining zones of uncertainty. The planetary boundaries are refined as climate change, novel entities (e.g., new substances such as heavy metals and modified life

\footnotetext{
Please cite this article as: Muthama N. J., (2019). Sub-National Policy Readiness as Regards the Planet's Carrying Capacity and Environmental Sustainability in Kenya. Journal of Sustainability, Environment and Peace 1(1) 6-11
}

forms - not yet quantified), ozone depletion, aerosol loading (not yet quantified), ocean acidification, biogeochemical flows (nitrogen and phosphorous), freshwater use, land-system change, and biosphere integrity (genetic and, not yet quantified, functional diversity).

Planetary boundaries cannot be directly applied at a local level; however, cities as key drivers, and those most impacted by global influences, need to have proper attribution of emissions and impacts quantified. This challenge arose in attributing greenhouse gas emissions to corporations and sub-national governments. National inventories, for example, are solely production based, accounting for all activities within national borders.

Sub-national regions, County governments in Kenya included, are arguably also responsible for upstream emissions and impacts for production and transportation that occur outside their borders. 
ISO 14074 provides a methodology to comprehensively estimate all emissions from production to final use of a product, and is based on Scopes 1 (direct), 2 (indirect from purchased energy), and 3 (indirect, embodied, ISO 2006). A similar approach, quantifying direct and indirect (embodied) impacts, can be used to assess overall impacts of food production through growing use of irrigation water (Valipour et al. 2015), as well with nitrogen and phosphorous use and addressing the "degree of subjectivity in setting boundaries," and the need to capture differentiated application of boundaries, e.g., 'over-use' of fertilizer in China vs 'under-use' in Rwanda (Nordhaus et al. 2012).

Building on the bio-physical boundaries of Rockstrom et al. (2009) and Steffen et al. (2015) and the socioeconomic approach by Raworth (2012), Dearing et al. (2014) propose a 'safe and just operating space for human wellbeing,' that includes both physical and social boundaries.

While Dearing et al. (2014) indicators provide insights into a region's social-ecological state, other important aspects of basic urban services, such as transportation, security and safety, geophysical risks, and biodiversity are also needed, particularly if long-term involvement of cities is sought.

An important contribution to the concept of environmental sustainability was made by the OECD Environmental Strategy for the First Decade of the $21^{\text {st }}$ Century (OECD, 2001). The OECD document defines needed criteria for environmental sustainability, in the context of regeneration, assimilation and reversibility, as: regeneration (renewable resources shall be used efficiently and their use shall not be permitted to exceed their long-term rates of natural regeneration), assimilation (releases of hazardous or polluting substances into the environment shall not exceed their assimilative capacity, if any) and avoiding irreversibility. Environmental sustainability is consequently one of the biggest challenges and most critical goals of present generation. Environmental sustainability is the key strategy against the backdrop of the growth of human population and the rampant anthropogenic exploitation of environment.

In an attempt to develop 'contours of a resilient global future,' Gerst et al. (2013) combined scenario analysis (to 2100), planetary boundaries, and targets for human development. Gerst et al. (2013) extend the initial physical boundaries assessment with the addition of hunger, inequity, and water stress. The analysis is at a global scale and supports long-term scenario planning and is sufficiently robust to accommodate dramatic social and technological change. Very limited literature exists on investigations of the role of planetary boundaries at sub-nation level, especially in Kenya. The approach presented in this paper provides a way to view planetary and county boundaries in Kenya as development targets from a county development plan perspective.

\section{Materials and Methods}

Since its publication in 2009, the planetary boundaries hypothesis has become a leading framework for thinking about global environmental problems. The planetary boundaries hypothesis posits that there are nine hard, global biophysical limits to human development, namely: land-use change, biodiversity loss, nitrogen and phosphorous levels, freshwater use, ocean acidification, climate change, ozone depletion, aerosol loading, and chemical pollution. Further it is suggested that crossing any of these boundaries may have catastrophic consequences for human welfare.

Content analysis methodology was adopted in this study. Content analysis involves specialized procedures that, at least in quantitative content analysis, allow for replication. The findings of a good study using quantitative content analysis, therefore, do not rely solely on the authority of the researchers doing the content analysis for their acceptability. They can be subjected to independent tests and techniques for judging their validity and reliability. Indeed, the extent to which validity and reliability can be judged are significant issues in evaluating a research methodology, and they are considered in subsequent sections in relation to both quantitative and qualitative content analysis. Content analysis is a research tool used to determine the presence of certain words or concepts within texts or sets of texts. Researchers quantify and analyse the presence, meanings and relationships of such words and concepts, then make inferences about the messages within the texts, the writer(s), the audience, and even the culture and time of which these are a part. To conduct a content analysis on any such text, the text is coded, or broken down, into manageable categories on a variety of levels--word, word sense, phrase, sentence, or theme--and then examined using one of content analysis' basic methods: conceptual analysis or relational analysis (Bush et al, 2012).

Two general categories of content analysis: conceptual analysis and relational analysis. Conceptual analysis can be thought of as establishing the existence and frequency of concepts most often represented by words of phrases in a text. For instance, a review article on climate governance uses the word drought quite. With conceptual analysis you can determine how many times words such as drought, hunger, or starving appear in a volume of the review article. In contrast, relational analysis goes one step further by examining the relationships among concepts in a text. Returning to the drought example, with relational analysis, one could identify what other words or phrases drought or hunger appear next to and then determine what different meanings emerge as a result of these groupings (Bush et al, 2012).

As a research methodology, content analysis has its roots in the study of mass communications in the 1950s. Based on a basic communications model of sender / message / receiver, initially researchers emphasized making inferences based on quantified analysis of recurring, easily identifiable aspects of text content, sometimes referred to as manifest content. Since then, researchers in many fields, including anthropology, library and information studies (LIS), management, political science, psychology, and sociology, have used content analysis. 
In the process, they have adapted content analysis to suit the unique needs of their research questions and strategies and have developed a cluster of techniques and approaches for analysing text grouped under the broad term of textual analysis (White and Marsh, 2006). All in all, it may be summarised that Contents analysis has pros and cons as follows:

Content analysis offers several advantages to researchers who consider using it. In particular, content analysis (Bush et al, 2012):

- Directly analyses at communication via texts or transcripts, and hence gets at the central aspect of social interaction

- permits both quantitative and qualitative operations

- offers valuable historical/cultural insights over time through analysis of texts

- provides for a closeness to text which can alternate between specific categories and relationships and also statistically analyses the coded form of the text

- may be useful interpreting texts for purposes such as the development of expert systems (since knowledge and rules can both be coded in terms of explicit statements about the relationships among concepts)

- is an unobtrusive means of analysing interactions provides insight into complex models of human thought and language use

On the other hand, Content analysis suffers from several disadvantages, both theoretical and procedural. In particular, content analysis:

- can be extremely time consuming

- is subject to increased error, particularly when relational analysis is used to attain a higher level of interpretation

- is usually devoid of theoretical base, or attempts too liberally to draw meaningful inferences about the relationships and impacts implied in a study

- is essentially reductive, particularly when dealing with complex texts

- tends too often to simply consist of word counts

- often ignores the context that produced the text, as well as the aftermath of the produced text

can prove too complex to automate

This paper performed content analysis of the above nine limits, with their subsets, as they are described and/or discussed in the county Integrated Development Plans (CIDPs) 2018-2023. A total of 22 CIDPs for 22 counties (Table 1). The choice of the counties was based on the availability of their respective CIPDs on their websites or other relevant sites. The target was to retrieve all the CIDPs from the 47 counties but only 22 were available online. In addition, the CIDPs were analysed to elucidate the implied environmental sustainability. Correlation analysis of the counts of their mentions were presented and discussed.
Table 1. Counties whose CIDPs were analysis

\begin{tabular}{llll}
\hline S.No. & Name of County & S.No. & Name of County \\
\hline 1 & Bomet & 12 & Kitui \\
2 & Bungoma & 13 & Laikipia \\
3 & Busia & 14 & Meru \\
4 & Nairobi & 15 & Muranga \\
5 & Mombasa & 16 & Narok \\
6 & Uasin Gishu & 17 & Nyeri \\
7 & Elgeyo Marakwet & 18 & Taita Taveta \\
8 & Garissa & 19 & Tharaka Nithi \\
9 & Kakamega & 20 & Trans Nzoia \\
10 & Kericho & 21 & Vihiga \\
11 & Kisii & 22 & West-Pokot \\
\hline
\end{tabular}

Table 2. Issues incorporated for content analysis

\begin{tabular}{ll}
\hline \multicolumn{2}{l}{ Key words used in content analysis } \\
Aerosol loading & Land-Use \\
Afforestation & Land-Use Change(s) \\
air pollution & Nitrogen \\
Biodiversity & Ocean \\
Biodiversity loss & Ocean Acidification \\
Chemical Pollution & ozone \\
Climate Change & Peace \\
Deforestation & pollution \\
dust & Stratospheric ozone De- \\
Freshwater & pletion \\
Global Freshwater Use & trees \\
Global Nitorgen Cycle & water \\
Global Phosphorous Cycle & water pollution \\
land pollution & water use \\
\end{tabular}

\section{Results and Discussions}

Analysis, of the extent to which the issues pertaining to the nine limits are elaborated in each of the 22 CIDPs, was performed using frequency analysis of content (Figure 1 and Table 3). It was observed that the CIDPs cover between 30 to $60 \%$ of the expected content of the limits. This is a pointer to the readiness of the plans in addressing planetary boundaries at local level. It may be suggested that inclusion of complementary necessary content in future, especially if opportunities of mid-term review will arise, will prove timely and beneficial.

Comparative analysis of the counts of the limits showed that Kitui, Elgeyo Marakwet and Nyeri counties have most comprehensive CIDPs as far as planetary boundaries are concerned (Figure 2). Subsequently, they the most strategically endowed counties to address the planetary boundaries. On the centrally, Laikipia, Muranga, and Kericho seem the least strategically positioned to address these planetary boundaries. Necessary mitigating measures may need to be taken by these counties.

It is notable that water issues are the most prominent among the counties (Figure 3). This is an indication that all efforts must be put to address freshwater availability, access and affordability as a matter of urgency. 
Table 3. Key issues analysed per corresponding Planetary Boundary

\begin{tabular}{|c|c|c|}
\hline & Planetary Boundary & Key words \\
\hline 1 & climate change: & $\begin{array}{l}\text { Climate Change; Defor- } \\
\text { estation; Dust; Air pollu- } \\
\text { tion; Poluution }\end{array}$ \\
\hline 2 & ozone depletion, & $\begin{array}{l}\text { Ozone; Stratospheric } \\
\text { ozone Depletion }\end{array}$ \\
\hline 3 & aerosol loading, & Aerosol loading; dust \\
\hline 4 & ocean acidification, & $\begin{array}{l}\text { Ocean; Ocean Acidifica- } \\
\text { tion; pollution } \\
\text { Water; water pollution; } \\
\text { water use }\end{array}$ \\
\hline 5 & biogeochemical flows, & $\begin{array}{l}\text { air pollution; Biodiversity } \\
\text { loss; Chemical Pollution }\end{array}$ \\
\hline 6 & freshwater use, & $\begin{array}{l}\text { Freshwater; Global Fresh- } \\
\text { water Use; water } \\
\text { water pollution; water use }\end{array}$ \\
\hline 7 & land-system change & $\begin{array}{l}\text { land pollution; Land-Use; } \\
\text { Land-Use Change(s) }\end{array}$ \\
\hline 8 & biosphere integrity & $\begin{array}{l}\text { Biodiversity; Biodiversity } \\
\text { loss; Chemical Pollution; } \\
\text { Trees }\end{array}$ \\
\hline 9 & novel entities, & $\begin{array}{l}\text { Global Nitorgen Cycle; } \\
\text { Global Phosphorous Cy- } \\
\text { cle; Nitrogen; }\end{array}$ \\
\hline
\end{tabular}

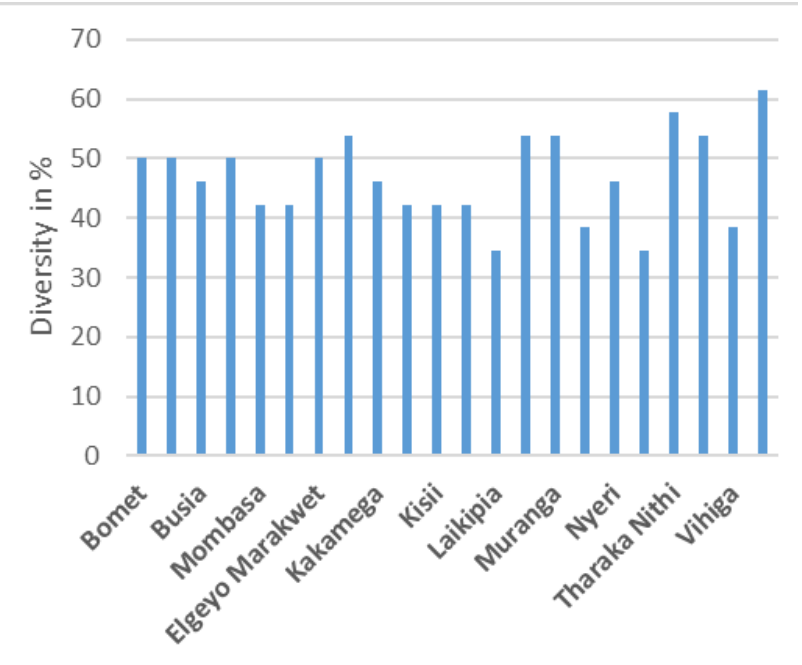

Figure 1. The Percentage diversity of CIDPs

The most critical boundary issue, as regards counties in Kenya is water. Kenya's natural renewable water resources heavily depend on the few and fragile catchments covered by montane forests in the country's highland areas where humid climate zone is prevalent. They are the headwater catchments of Kenya's main rivers that make up the five basin areas in the country namely: Lake Victoria, Rift Valley, Athi, Tana and Ewaso Ng'iro North. It is estimated that the catchments contributes over $75 \%$ of the nation's surface water resources (Ministry of Environment, Water and Natural Resources, 2013).

Kenya's surface water resources is estimated to be 22,564 million $\mathrm{m} 3$ representing $91.5 \%$ of the total available water resources, the rest is groundwater. As of 2010 , the annual water demand was $14 \%$ of the available water resources; groundwater supplied $16 \%$ of the demand. Nearly $50 \%$ of the demand was from irrigation sector despite being for only $17 \%$ of the potentially irrigable land. Scarcity of water coupled with low investment has been blamed for the low irrigation development in Kenya (Kenya National Bureau of Statistics, 2007); Ministry of Water and Irrigation, 2009). As much as a lot of policy and practice initiatives and intervention are ongoing, more still need to be done to ensure the irreversible tipping point is not reached.

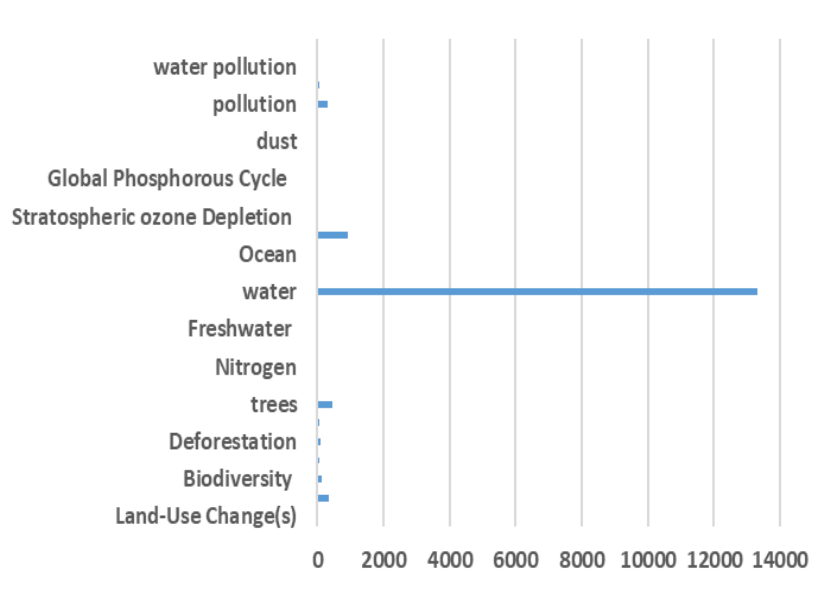

Figure 3. Cumulative sum of CIDP issues for the nine limits

It may further be observed from the Figure 3 that several indicators of the limits are barely mentioned or addressed within quite a number of the plans.

Synthesis of the indicators in the absence of water as a variable, reveals that climate change, tree and land-use rank highest (Figure 4).

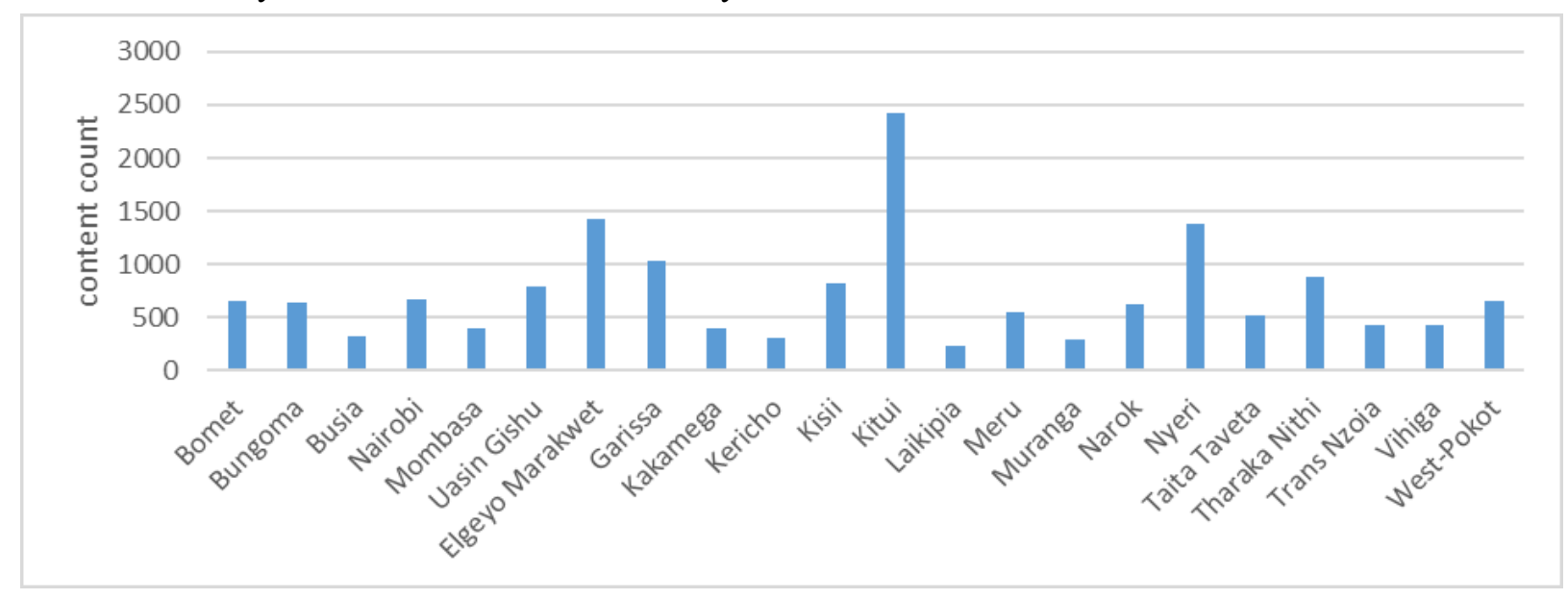

Figure 2. Content counts, within the 22 CIDPs, pertinent to the nine limits. 
A recent study on climate governance in Kenya (PACJA, 2019) indicates that the state of climate governance integration in Kenya's devolved system of governance is such that majority $(59 \%)$ of counties lack effective and resilient climate governance structures. There are generally low capacities to monitor local ecosystems and climate impacts; participate in national and international climate processes; develop public education and stakeholder engagement around adaptation and, solicit and fruitfully deploy funds related to climate change. However, the national government has effective governance structures. As much as a lot of policy and practice initiatives and intervention are ongoing, more still need to be done to ensure the irreversible tipping point is not reached.

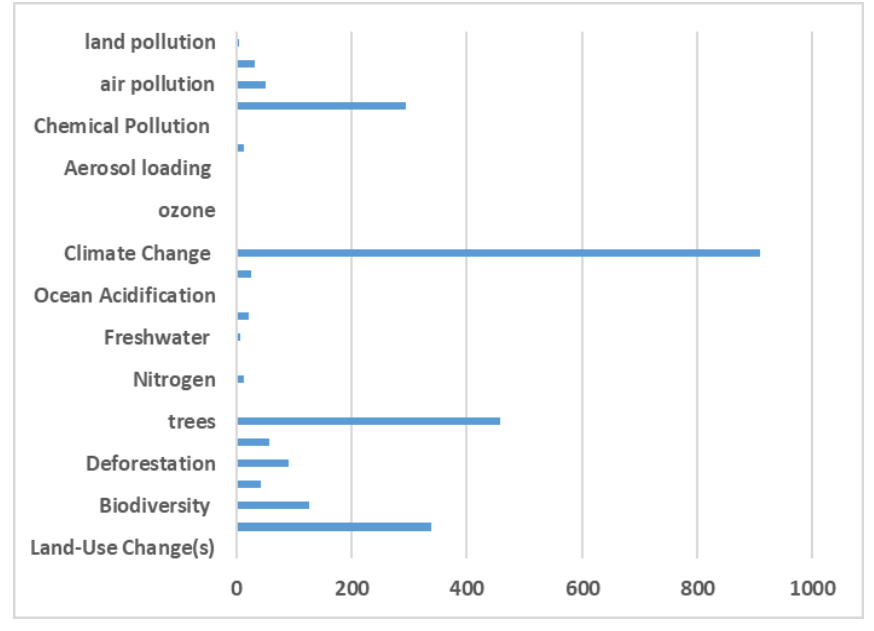

Figure 4. Cumulative CIDP issues for the nine limits, without water

On the other hand, some of the limited which recorded minimal attention, including ozone and aerosol loading, need to be captured at county level. Although several studies have articulated their importance, for instance Muthama al., (2003), Angu eta al (2016), Makokha et al., 2015) a lot needs to be done in terms of awareness creation of their vital importance.

Finally, correlation analysis of the counts on planetary boundaries versus Peace issues revealed positive correlation between biodiversity and peace (Figure 5), with a correlation coefficient of 0.575 . It is interesting to observe that the counties having strategies on biodiversity have associate peace initiatives.
This points to the need to enhance awareness of the importance of strategic positioning biodiversity conservation in every county.

\section{Conclusion}

Locally relevant, applied and quantitative methodologies are critical to capture the complexity of infrastructure systems, global inter-connections, and to monitor local and global progress toward sustainability. Following efforts to define and quantify safe planetary boundaries in areas such as climate change, biosphere integrity, and freshwater use, this paper modifies the methodology to monitor boundaries from a country's perspective. The methodology provides an important tool for counties to play a more strategic and active role in global sustainable development. In this regard, a comparative analysis of 22 CIDPs is presented in the context of planetary boundaries. The methodology elucidated areas of strength and others for further improvement. Water and climate change are highest ranking issues which beg for robust and definite roadmaps to avert reaching the tipping points. It is recommended that counties endeavour to address the nine planetary boundaries in a comprehensive and substantive way at county level and to take an active role in bringing about shifts in awareness as regards relevant mitigating actions for each of the nine limits.

\section{References}

Ang'u, C., Nzioka J. Muthama and Bethwel K. Mutai (March 2016). Aerosol optical depth patterns associated with urbanization and weather in Nairobi and Lamu. J. Meteorol. Rel. Sci. 8:3; http:// dx.doi.org/10.20987/jmrs.2412-3781.803; ISSN: 2412-3781.

Busch Carol, Paul S. De Maret, Teresa Flynn, Rachel Kellum, Sheri Le, Brad Meyers, Matt Saunders, Robert White, and Mike Palmquist.. (1994 - 2012). Content Analysis. Writing@CSU. Colorado State University. Available at https://writing.colostate.edu/ guides/guide.cfm?guideid=61.

Hoornweg D., M. Hosseini, C. Kennedy and A. Behdadi (2016). An urban approach to planetary boundarie. Ambio, A Journal of the Human Environment. ISSN 0044-7447 Volume 45, Number 5, Ambio (2016) 45:567-580. DOI 10.1007/s13280-016-0764-y

Dearing, J.A., R. Wang, K. Zhang, J.G. Dyke, H. Haberl, M.S. Hossain, P.G. Langdon, T.M. Lenton, et al. 2014. Safe and just operating spaces for regional social-ecological systems. Global Environmental Change 28: 227-238.

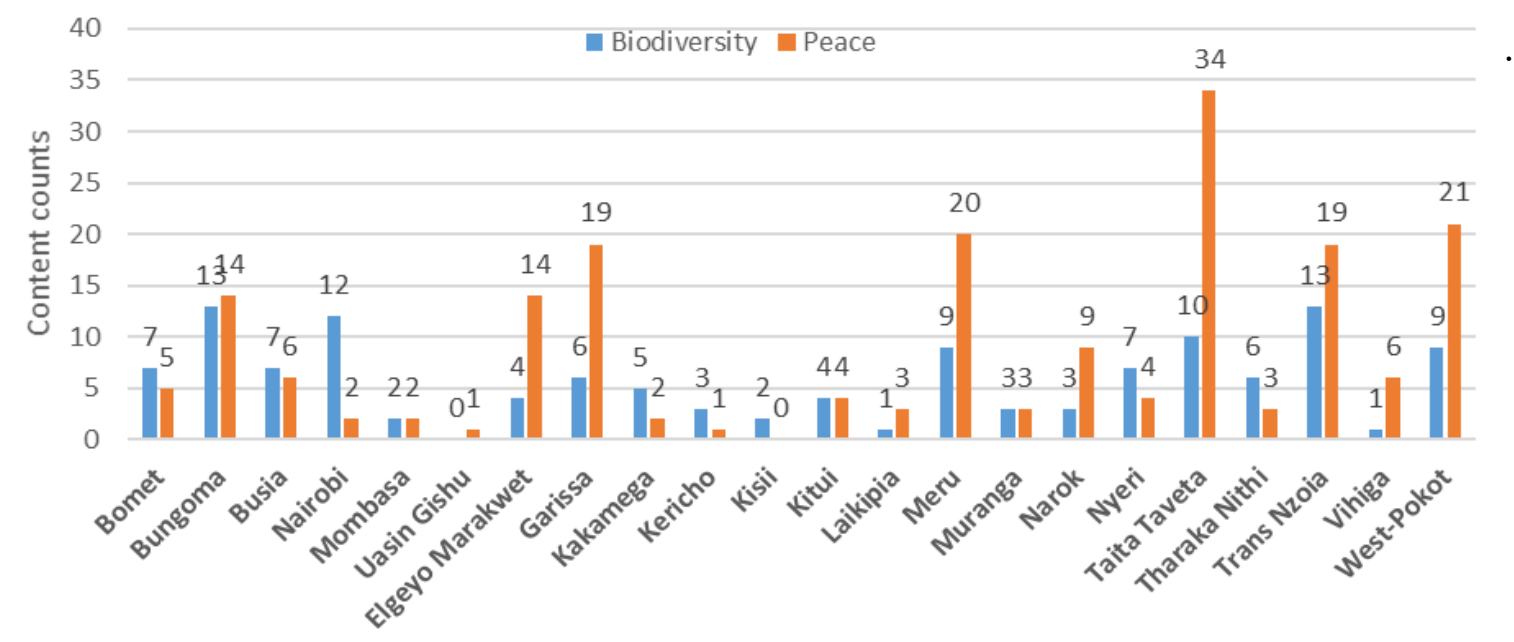

Figure 5. Correlation between Biodiversity and Peace in CIDPs 
Kenya National Bureau of Statistics (2007) Basic Report on WellBeing in Kenya. Kenya National Bureau of Statistics, Nairobi.

Makokha J. W., H. K. Angeyo ${ }^{1}$ and J. N. Muthama(2015). Sunphotometric Study and Multivariate Analysis of Aerosol Optical Depth Variability oversome representative sites of the Kenyan Atmosphere. International Journal of BioChemiPhysics, Vol.23, Dec. 2015, pp 15-28.

Ministry of Environment, Water and Natural Resources (2013) The National Water Master Plan 2030. Ministry of Environment, Water and Natural Resources, Nairobi.

Ministry of Water and Irrigation (2009) Water Sector Strategic Plan (WSSP) 2009-2014. Ministry of Water and Irrigation, Nairobi.

Muthama, N. J., A. O. Opere and C. Oludhe: Equatorial Total ozone as a predictor of sea surface temperatures useful for East African seasonal rainfall prediction. J. Afric.Met.Soc. Vol. 6. No. 2, pp 1-10, 2003.

Nordhaus, T., M. Shellenberger, and L. Blomqvist. 2012. The planetary boundaries hypothesis: A review of the evidence. Oakland: Breakthrough Institute Raworth, K. 2012. A safe and just space for humanity. Oxford: Oxfam International.
OECD, 2001. Environmental Strategy for the First Decade of the 21st Century,

http://www.oecd.org/environment/indicators-modellingoutlooks/1863539.pdf (last retrieved, December 19, 2018).

PACJA, 2019. Strengthening Climate Change Governance in Kenya. Status report Printed in collaboration with Wangari Maathai institute for Peace and Environmental Studies. (In Print)

Rockstrom, J., W. Steffen, K. Noone, A. Persson, F.S. Chapin, E.F. Lambin, T.M. Lenton, M. Scheffer, et al. 2009. A safe operating space for humanity. Nature 461: 472-475

Steffen, W., K. Richardson, J. Rockstro"m, S.E. Cornell, I. Fetzer, E.M. Bennett, R. Biggs, S.R. Carpenter, et al. 2015. Planetary boundaries: Guiding human development on a changing planet.Science 327: 6223 .

Valipour, M., M. Ahmadi, M. Raeini-Sarjaz, M. Sefidkouhi, A. Shahnazari, R. Fazlola, and A. Darzi- Naftchali. 2015. Agricultural water management in the world during past half century. Archives of Agronomy and Soil Science 61(5): 657-678.

White, D. M. and E. E. Marsh, 2006. Content Analysis: A Flexible Methodology. LIBRARY TRENDS, Vol. 55, No. 1 